\title{
Evaluation of adult dTPaP vaccination coverage in France: experience in Lyon city, 2010-2011
}

\author{
Dominique Baratin ${ }^{1}$, Corinne Del Signore ${ }^{2}$, Jacques Thierry ${ }^{3}$, Evelyne Caulin ${ }^{4}$ and Philippe Vanhems ${ }^{1,2^{*}}$
}

\begin{abstract}
Background: Compliance with official recommendations can be assessed by evaluating vaccination coverage (VC) in populations. The main objective of our study was to assess VC of adults against diphtheria, tetanus, poliomyelitis and pertussis (dTPaP) according to age. The second objective was to explore if vaccination status could be confirmed by documentation.

Methods: A cross-sectional study was conducted in 680 adults consulting for biological examination in private laboratories in Lyon (France) to evaluate VC for diphtheria, tetanus, poliomyelitis and pertussis (dTPaP) and enabled reported vaccinations to be compared with documented, confirmed vaccinations.

Results: Verification of documented, confirmed vaccinations disclosed VC of $78.7 \%$ for tetanus, $63.6 \%$ for poliomyelitis, $57.8 \%$ for diphtheria and $10.7 \%$ for pertussis. Comparison of confirmed and self-reported vaccinations revealed that a large percentage of people who thought that they were vaccinated were not. VC significantly decreased with age for diphtheria and poliomyelitis and did not vary by gender. The VC rate for pertussis has increased since the 2008 recommendations were made.
\end{abstract}

Conclusions: The main thrust of this study was to compare reported and confirmed data. A significant percentage of people wrongly believed that they were up to date with their vaccination.

Keywords: Vaccination coverage, Adults, Diphtheria, Tetanus, Poliomyelitis, Pertussis

\section{Background}

Vaccination recommendations are updated in line with changes in epidemiological data, the efficacy and tolerability of existing vaccines, and the advent of new vaccines on the market. Studies in France and Europe [1,2] have highlighted the need to improve vaccination policies. Ignorance of the exact level of vaccination coverage (VC) in the general population does not facilitate comparisons over time or evaluation of vaccination impact. VC monitoring of at-risk populations and within specific age groups would be useful, aided by the establishment of indicators in the general population for the main vaccinationpreventable diseases. Available sources of information are personal child health records for young adults, new personal adult health records, university files, international

\footnotetext{
* Correspondence: philippe.vanhems@chu-lyon.fr

${ }^{1}$ Hospices Civils de Lyon, Hôpital Edouard Herriot, Service d'Hygiène,

Epidémiologie et Prévention, Lyon, France

2Institut d'Epidémiologie, Laboratoire de Biométrie et Biologie Evolutive, UMR

CNRS 5558, Claude Bernard Lyon 1 University, Lyon, France

Full list of author information is available at the end of the article
}

vaccination records, occupational health records, medical records, medical insurance companies and prescribing physicians.

A sero-epidemiological investigation of adults reported that the percentage of subjects with diphtheria and tetanus antibodies decreased with age and that $7.6 \%$ of the population studied (13.4\% of those aged 18-29 years) had recently been infected by pertussis [3]. These results underline the need for better application of the recommendations for pertussis booster vaccines in adults [4]. The lack of any systematic follow-up of $\mathrm{VC}$ and the heterogeneous nature of various practices [5] might partly explain such observations. The population's perception of vaccination is also a determining factor, and individuals' knowledge of their vaccination status is probably not optimal.

The primary objective of our study was to evaluate adult diphtheria, tetanus, polio and pertussis (dTPaP) $\mathrm{VC}$ by age in the general population. The secondary objectives were to compare self-reported $\mathrm{dTPaP} \mathrm{VC}$ with 
documented VC obtained from vaccination records and to verify dTPaP vaccination in adults.

\section{Methods}

\section{Study setting and data collection}

Our cross-sectional study was conducted in cooperation with 6 private medical analysis laboratories located in different districts of Lyon, a city with more than 480,000 inhabitants. Each laboratory covered about 14,000 inhabitants. Laboratory participation was voluntary and previously effective in collaborative academic epidemiological studies [5].

Subjects included in the survey were aged over 19 years and had to have attended a medical analysis laboratory for tests of any kind (glycaemia, serology, etc.). All patients were contacted but only those volunteering to participate were enrolled. After informing each study subject and obtaining signed consent, research assistants collected vaccination data with a standardised questionnaire complemented by sociodemographic data. Vaccination documentation was always requested. Data on subjects' knowledge of their vaccination status focused on diphtheria, tetanus, poliomyelitis, pertussis, and the conditions under which these vaccinations were given. Questions were asked in relation to pertussis: intention to become parents, pregnancy, contact with children under 6 months old and knowledge of the disease. Vaccination data were validated by documentary "evidence" of vaccination. Descriptive analysis was performed relative to socio-demographic factors and vaccination data supported by documentary "evidence". Subjects vaccinated within the past 10 years were considered to be up to date with their vaccination according to the 2011 French adult immunization schedule (Table 1).

Our survey was conducted from October 13, 2010 to February 11, 2011, after approval by the Advisory Committee on Data Processing in Medical Research and the French National Data Protection Committee.

\section{Statistical analysis}

Qualitative variables were reported as number and percentage, and quantitative variables, as means and standard deviation. VC was calculated for 100 subjects with 95\% confidence interval (95\% CI). Categorical variables were compared by the Chi square test or Fisher's exact test as appropriate (less than 5 individuals by cell in 2X2 tables). All data were analysed anonymously with SPSS 17.0 software for Windows (SPSS Statistics Inc., Chicago, IL, USA).

\section{Results \\ Study population characteristics}

A total of 680 subjects, aged over 19 years, were surveyed among all patients who attended 6 laboratories during the study period. Median age was 60 years (min: 20, max: 91), and the gender ratio $(\mathrm{M} / \mathrm{F})$ was 0.68 . Pensioners $(56.9 \%)$ were the most commonly-represented occupational group, followed by business executive and managers (11.6\%), the unemployed, disabled or students $(8.0 \%)$, healthcare professionals (9.3\%), labourers (3.1\%), artisans-shopkeepersbusiness people $(0.9 \%)$ and farmers $(0.4 \%)$. Master's degree (20.6\%) was the most frequently-found educational level. Healthcare professionals who administered vaccinations were, in the great majority of cases, family physicians (77\%), vaccination centres (9.6\%), occupational physicians (8.8\%), hospital centres and nurses $(0.8 \%)$.

In the specific case of pertussis, $15.6 \%$ of subjects intended to become parents shortly after the survey, $8.2 \%$ were pregnant (or their partner was), and 19.1\% had frequent contact with children under 6 months of age. On interview, a third of people who intended to become parents, a third of pregnant women (or their partners) and a third of people in contact with children under 6 months of age thought about getting vaccinated against pertussis. Twenty-nine percent were aware of the value of pertussis vaccination, and $21 \%$ of them knew how serious pertussis infection was in adults.

Table 12011 French immunisation schedule - Recommendations for adults

\begin{tabular}{|c|c|c|c|c|c|c|c|}
\hline \multirow{3}{*}{$\begin{array}{l}\text { General } \\
\text { recommendations }\end{array}$} & Vaccines & 18-23 years & 24 years & $26-28$ years & $30-45$ years & 46-64 years & $\geq 65$ years \\
\hline & $\begin{array}{l}\text { Diphtheria (d) } \\
\text { Tetanus (T) } \\
\text { Poliomyelitis (IPV) }\end{array}$ & & & \multirow{2}{*}{$\begin{array}{l}\text { dT-IPV to be replaced by a single } \\
\text { dose of dTaP-IPV for adults who } \\
\text { have not received pertussis } \\
\text { vaccination since } 10 \text { years }\end{array}$} & \multirow{2}{*}{\multicolumn{3}{|c|}{1 dose of dT-IPV every 10 years }} \\
\hline & Acellular pertussis (aP) & & & & & & \\
\hline Catch-up program & \multicolumn{3}{|l|}{ Acellular pertussis (aP) } & & \multicolumn{3}{|c|}{$\begin{array}{l}\text { Replaced by a single dose of dTaP-IPV } \\
\text { for adults who have not previously } \\
\text { received pertussis vaccination }\end{array}$} \\
\hline $\begin{array}{l}\text { Specific and at-risk } \\
\text { populations }\end{array}$ & Acellular pertussis (aP) & \multicolumn{6}{|c|}{$\begin{array}{l}\text { A single dose of dTaP-IPV in adults with the prospect of becoming parents (cocoon), family members } \\
\text { during pregnancy and post-partum women (minimum interval of } 2 \text { years between } 1 \text { dose of dT-IPV } \\
\text { and dTaP-IPV }\end{array}$} \\
\hline
\end{tabular}


Finally, a total of $33.1 \%(225 / 680)$ of those surveyed reported having vaccination documentation. This documentary evidence assumed different forms: vaccination record $(52.9 \%)$, vaccination card or certificate $(34.2 \%)$, and personal health record (12.9\%). Table 2 describes the characteristics of study subjects and the Lyon city population.

Table 2 Characteristics of individuals with documentation and of the Lyon city population for dTPaP VC evaluation, October 2010-February 2011

\begin{tabular}{|c|c|c|}
\hline Characteristics & $\begin{array}{c}\text { Study } \\
\text { population } \\
n=225\end{array}$ & $\begin{array}{c}\text { Lyon city } \\
\text { population * } \\
\geq 20 \text { years } \\
n=372,583\end{array}$ \\
\hline \multicolumn{3}{|l|}{ Age (years) } \\
\hline Median $\left[\mathrm{QQR} \mathrm{R}^{* *}\right]$ & $63[51-73]$ & $40[28-58]$ \\
\hline \multicolumn{3}{|l|}{ Strata } \\
\hline $20-40$ & $15.1 \%$ & $47 \%$ \\
\hline $41-60$ & $27.1 \%$ & $28 \%$ \\
\hline $61-80$ & $46.7 \%$ & $17 \%$ \\
\hline$>80$ & $11.1 \%$ & $6 \%$ \\
\hline \multicolumn{3}{|l|}{ Sex } \\
\hline Male & $35.6 \%$ & $46 \%$ \\
\hline Female & $64.4 \%$ & $54 \%$ \\
\hline \multicolumn{3}{|l|}{ Socio-professional categories } \\
\hline Pensioners & $59.9 \%$ & $19.2 \%$ \\
\hline Employees & $9.8 \%$ & $15.4 \%$ \\
\hline Business executive or managers & $11.6 \%$ & $16.9 \%$ \\
\hline Unemployed, student or disabled & $8.0 \%$ & $21.1 \%$ \\
\hline Healthcare professionals & $9.3 \%$ & $17.4 \%$ \\
\hline Labourers & $3.7 \%$ & $7.6 \%$ \\
\hline Artisans, shopkeepers, business people & $0.9 \%$ & $2.5 \%$ \\
\hline Farmers & $0.4 \%$ & $0.0 \%$ \\
\hline \multicolumn{3}{|l|}{ Educational level } \\
\hline Master's degree level 2 (Bachelor $+\geq 3$ ) & $30.2 \%$ & $28.4 \%$ \\
\hline Master's degree level 1 (Bachelor + 2) & $12.4 \%$ & $15.9 \%$ \\
\hline Bachelor & $20.9 \%$ & $15.9 \%$ \\
\hline $\begin{array}{l}\text { GCSE***, Certificate in vocational training, } \\
\text { Technical School Certificate }\end{array}$ & $20.9 \%$ & $18.9 \%$ \\
\hline Basic school-leaving qualification & $12.0 \%$ & $6.8 \%$ \\
\hline No schooling & $3.6 \%$ & $13.9 \%$ \\
\hline \multicolumn{3}{|l|}{ Number of children } \\
\hline 0 & $20.9 \%$ & $48.2 \%$ \\
\hline 1 & $16.4 \%$ & $24.1 \%$ \\
\hline 2 & $36.4 \%$ & $18.7 \%$ \\
\hline 3 & $16.1 \%$ & $6.6 \%$ \\
\hline$\geq 4$ & $10.1 \%$ & $2.4 \%$ \\
\hline
\end{tabular}

* data from the french national agency for demographic data (www.insee.fr). ** InterQuartile range *** General Certificate of Secondary Education.
Concerning self-reported vaccination, those who produced documentation, as opposed to those who did not, were predominantly women $(64.4 \%$ vs $56.7 \%$, $\mathrm{p}=0.05$ ), older people (mean age: 60.7 vs 55.5 years, $\mathrm{p}=0.001$ ) and people who thought they were up to date with their vaccinations apart from pertussis vaccination (Table 3).

\section{Vaccine coverage by age}

Verification of vaccinations confirmed by documentary evidence $(n=225)$ showed VC of $57.8 \%$ for diphtheria, $78.7 \%$ for tetanus, $63.6 \%$ for poliomyelitis and $10.7 \%$ for pertussis (Table 4). VC for each of the 4 valences studied did not vary with gender. VC for diphtheria and poliomyelitis, but not for tetanus or pertussis, decreased significantly with age (Table 4). For confirmed vaccinations, 128 people received combined dT-IPV vaccination (vaccines injected on the same day and in a single dose: dT-IPV and dTaP-IPV are the most commonlyadministered vaccines in France). VC with combined vaccination did not differ significantly with gender, but decreased with age. Some people received a single valence (tetanus), for which a $\mathrm{VC}$ gradient with age was observed (Table 4).

Since the publication of pertussis recommendations in March 2008, VC rates appear to have increased (data not reported) but no pregnant women (0/11) in our study were up to date with their pertussis vaccination. No significant difference for pertussis vaccination appeared between men and women (p: 0.50). Moreover, $4 \%(1 / 26)$ of subjects intending to become parents were vaccinated, and $16 \%(6 / 36)$ of those in contact with infants under 6 months of age were vaccinated.

\section{Vaccine status according to documentation reported or not}

Subjects who thought the most that they were up to date with vaccination, compared to those were not, provided documentation $(81 \% / 60 \%, \mathrm{p}<0.001)$. In total, people with documentation believed that they were up to date with their vaccinations, $70.2 \%$ for diphtheria, $95.6 \%$ for tetanus, $76.0 \%$ for poliomyelitis, and $22.2 \%$ for pertussis.

Comparison of confirmed and reported vaccinations by subject revealed that some who thought they were vaccinated for diphtheria; tetanus; poliomyelitis and pertussis were actually not (Table 5). Conversely, some subjects who thought they were not vaccinated were up to date with their vaccinations.

\section{Discussion}

The $\mathrm{VC}$ rates obtained were similar to those observed in national and regional evaluations [6-8]. These authors analysed the methods and tools employed in France to ascertain vaccination coverage in adults and concluded that it was difficult to collect information on $\mathrm{VC}$ in adult 
Table 3 Self-reported vaccination of Lyon city subjects producing documentation or not, October 2010-February 2011

\begin{tabular}{|c|c|c|c|c|}
\hline Self-reported vaccinations & $\begin{array}{l}\text { Subjects not producing } \\
\text { documentation }\end{array}$ & $\begin{array}{l}\text { Subjects producing } \\
\text { documentation }\end{array}$ & $\mathrm{p}$ & $\begin{array}{l}\text { Total subjects } \\
\text { included }\end{array}$ \\
\hline \multicolumn{5}{|l|}{ Sex n (\%) } \\
\hline Female & $258(56.7)$ & $145(64.4)$ & $<10^{-3}$ & $403(59.3)$ \\
\hline Male & $197(43.3)$ & $80(35.6)$ & & $277(40.7)$ \\
\hline \multicolumn{5}{|l|}{ Age (years) } \\
\hline Mean $( \pm \mathrm{SD})$ & $55.5( \pm 19.1)$ & $60.7( \pm 16.1)$ & 0.001 & $57.2[ \pm 18.3]$ \\
\hline Median [min-max] & 57 [20-91] & $63[21-87]$ & - & 60 [20-91] \\
\hline \multicolumn{5}{|l|}{ Age strata } \\
\hline $20-40$ & $123(27.0)$ & $34(15.1)$ & 0.02 & $157(23.1)$ \\
\hline $41-60$ & $129(28.4)$ & $61(27.1)$ & & $190(27.9)$ \\
\hline $61-80$ & $159(34.9)$ & $105(46.7)$ & & $264(38.8)$ \\
\hline$>80$ & $44(9.7)$ & $25(11.1)$ & & $69(10.1)$ \\
\hline $\begin{array}{l}\text { Subjects reporting being up to date with } \\
\text { their vaccinations } \mathrm{n}(\%)[95 \% \mathrm{Cl} \text { of \%] }\end{array}$ & $274(60.2)$ [55.9-68.7] & 183 (81.3) [75.8-86.0] & $<10^{-3}$ & $457(67.2)$ [63.3-70.7] \\
\hline \multicolumn{5}{|c|}{ Subjects reporting being up to date with each vaccination n (\%) $[95 \% \mathrm{Cl}$ of \%] } \\
\hline Diphtheria & $293(64.4)[59.9-68.7]$ & $158(70.2)[64.0-75.9]$ & 0.002 & $51(66.3)[62.7-69.8]$ \\
\hline Tetanus & $383(84.4)[80.6-87.3]$ & 215 (95.6) [92.9-97.7] & $<10^{-3}$ & 599 (88.1) [85.5-90.4] \\
\hline Poliomyelitis & $306(67.3)[62.8-71.4]$ & $171(76.0)[61.1-72.6]$ & 0.001 & $477(70.1)[66.6-73.5]$ \\
\hline Pertussis & 105 (23.1) [19.4-27.1] & $50(22.2)[15.1-24.8]$ & 0.96 & $155(22.8)[19.8-26.1]$ \\
\hline
\end{tabular}

populations through questionnaires. The best tool for assessing $\mathrm{VC}$ is serological testing, but it is very expensive and not easy to implement in population surveys.

The geographical and social diversity of participating laboratories ironed out any existing disparities. A recruitment bias could not be totally excluded, and recall bias was difficult to avoid. However, the likelihood that vaccination status was related to prescribed laboratory tests was very low and, in this case, selection bias would be limited. Care should be taken when generalising the results because the participating laboratories were not randomised.

The population interviewed was relatively elderly, retired and therefore more inclined to provide documentation by virtue of its greater availability. The population group likely to be parents (20-40 years) and reporting documentation (15.1\%) was under-represented compared to that observed in Lyon city (47\%). In addition, pertussis vaccination is not recommended during pregnancy in France, which does not allow us to compare the data to other countries.

Subjects agreeing to participate in the survey and to produce vaccination documentation might be more in tune with their health and more aware of the need to remain up to date with their vaccinations. A similar survey compared reported vaccinations with vaccinations confirmed by documentary evidence [9].
These findings might not be generalizable to the French population but may be representative of populations in large French cities (i.e. Paris, Marseille, and Strasbourg) or other large European cities.

dT-IPV VC decreases with age and requires the institution of vaccination campaigns among older people, underlining the importance of administering tetanus vaccine combined with other valences in accordance with official recommendations. Data collection tools for vaccination coverage appear to be incomplete and imprecise. Targeted surveillance to detect regional and social differences would be desirable [10].

\section{Conclusions}

VC measurement should be a public health priority to improve health education campaigns. Our study underlined the need to highlight prevention messages relating to vaccination. Its main value was documentary evidence. Comparison of reported data with confirmed data revealed a considerable percentage of subjects who wrongly believed their vaccinations to be up to date, particularly for pertussis. The percentage of people who thought they were vaccinated but who were not should prompt health authorities to develop VC monitoring programmes to prevent insufficient vaccination due to ignorance of individual status. The collection of vaccination coverage data needs to be improved and could be 
Table 4 Vaccination coverage and vaccine combination by age, Lyon city, October 2010-February 2011

\begin{tabular}{|c|c|c|c|c|}
\hline $\begin{array}{l}\text { Vaccination given } \\
\text { within } 10 \text { years }\end{array}$ & $n=225$ & $\begin{array}{l}\text { Non-vaccinated subjects } \\
\mathrm{n}(\text { Yes } \%)[95 \% \mathrm{Cl} \text { of } \%]\end{array}$ & $\begin{array}{c}\text { Vaccinated subjects } \\
\mathrm{n}(\text { Yes \%) [95\% Cl of \%] }\end{array}$ & $\mathrm{p}^{*}$ \\
\hline Diphtheria & & $92(42.2)[35.9-48.7]$ & $130(57.8)[51.2-64.1]$ & 0.001 \\
\hline 20-40 years & 34 & 9 (26.5) [13.8-43.1] & 25 (73.5) [56.9-86.3] & \\
\hline 41-60 years & 61 & $21(34.4)$ [23.3-46.9] & $40(65.6)[53.0-76.7]$ & \\
\hline $61-80$ years & 105 & 49 (46.7) [37.3-56.2] & 56 (53.3) [43.7-62.7] & \\
\hline$>80$ years & 25 & $16(64.0)$ [44.1-80.8] & 9 (36.0) [19.2-57.5] & \\
\hline Tetanus & & $48(21.3)[16.4-27.1]$ & 177 (78.7) [72.9-83.9] & 0.83 \\
\hline 20-40 years & 34 & 9 (26.5) [13.8-43.1] & 25 (73.5) [56.9-86.3] & \\
\hline 41-60 years & 61 & 14 (23.0) [13.7-34.7] & $47(77.0)$ [65.3-86.3] & \\
\hline $61-80$ years & 105 & 14 (13.3) [7.8-20.8] & 91 (86.7) [79.1-92.2] & \\
\hline$>80$ years & 25 & $11(44.0)$ [25.7-63.6] & $14(56.0)$ [36.4-74.3] & \\
\hline Polio & & 82 (36.4) [30.4-42.9] & 143 (63.6) [57.1-69.7] & 0.005 \\
\hline 20-40 years & 34 & 9 (26.5) [12.9-44.4] & 25 (73.5) [55.6-87.1] & \\
\hline $41-60$ years & 61 & $18(29.5)$ [18.5-42.6] & $43(70.5)[57.4-81.5]$ & \\
\hline $61-80$ years & 105 & 39 (37.1) [27.9-47.1] & 66 (62.9) [52.9-72.1] & \\
\hline$>80$ years & 25 & $16(64.0)$ [42.5-83.0] & 9 (36.0) [17.9-57.5] & \\
\hline Pertussis & & 201 (89.3) [84.8-92.9] & $24(10.7)$ [7.1-15.2] & 0.34 \\
\hline 20-40 years & 34 & 30 (88.2) [72.6-96.7] & $4(11.8)$ [3.3-27.5] & \\
\hline 41-60 years & 61 & $54(88.5)$ [77.8-95.3] & 7 (11.5) [4.7-22.2] & \\
\hline $61-80$ years & 105 & 92 (87.6) [79.7-93.3] & 13 (12.4) [6.7-20.3] & \\
\hline$>80$ years & 25 & $25(100)$ & $0(0)$ & \\
\hline dT-IPV ** & & 97 (43.1) [36.8-49.7] & $128(56.91)$ [50.4-63.3] & 0.01 \\
\hline 20-40 years & 34 & 9 (26.5) [13.8-43.1] & $25(73.5)$ [56.9-86.3] & \\
\hline 41-60 years & 61 & $21(34.4)$ [23.3-46.9] & 40 (65.6) [53.0-76.7] & \\
\hline $61-80$ years & 105 & 51 (48.6) [39.1-58.1] & $54(51.4)$ [41.9-60.9] & \\
\hline$>80$ years & 25 & 16 (64.0) [44.1-80.8] & 9 (36) [19.2-57.5] & \\
\hline Tetanus alone & & 187 (83.2) [77.8-87.8] & 38 (16.8) [12.4-22.2 ] & 0.01 \\
\hline 20-40 years & 34 & $34(100.0)$ & $0(0)$ & \\
\hline 41-60 years & 61 & 56 (91.8) [82.8-96.3] & 5 (8.2) [2.7-18.1] & \\
\hline $61-80$ years & 105 & 77 (73.3) [64.3-81.1] & $28(26.7)$ [18.9-35.7] & \\
\hline$>80$ years & 25 & $20(80.0)$ [61.1-92.3] & 5 (20) [6.8-40.7] & \\
\hline
\end{tabular}

*Statistical difference between those who were vaccinated and those who were not.

**Diphtheria, tetanus and poliomyelitis combined.

Table 5 Reported vaccinations (RV) versus confirmed vaccinations (CV), Lyon city, October 2010-February 2011

\begin{tabular}{lccc}
\hline $\begin{array}{l}\text { Subjects reporting } \\
\text { documentation } \mathbf{n = 2 2 5}\end{array}$ & RV $\mathbf{n}$ & $\mathbf{C V} \mathbf{n}$ & $\begin{array}{c}\mathbf{R V}-\mathbf{C V} / \mathbf{C V}^{*} \\
\text { Yes\% [95\% Cl of \%] }\end{array}$ \\
\hline Diphtheria & 158 & 100 & $36.7 \%[29.5-44.4]$ \\
Tetanus & 215 & 171 & $20.5 \%[15.5-26.3]$ \\
Poliomyelitis & 171 & 119 & $30.4 \%[23.9-36.6]$ \\
Pertussis & 50 & 9 & $82.0 \%[69.5-90.5]$ \\
\hline
\end{tabular}

* \% of people who thought that they were up to date and were not. centred in the community and/or hospital and/or workplace. Investigations should evaluate the characteristics of individuals who incorrectly report their vaccine status. This issue was not explored because of limited sample size. Improving vaccination coverage involves adapting measurement tools, developing public information campaigns, training doctors and ensuring a better understanding on the part of the general public.

\section{Competing interests}

EC was an employee of Sanofi Pasteur MSD at study time. Sanofi Pasteur MSD provided financial support for study conduct. All other authors declare that they have no competing interests regarding this study. 


\section{Authors' contributions}

$\mathrm{DB}, \mathrm{PV}, \mathrm{CDS}$ and EC contributed to study design DB and PV drafted the initial manuscript. JT provided access to laboratories. DB, EC and CDS contributed to data analysis and interpretation. All authors read, commented on and approved the final manuscript version.

\section{Acknowledgements}

We are grateful to Sanofi Pasteur MSD for partial financial support and to the managers and staff of independent medical analysis laboratories for their cooperation. Thanks to Ovid Da Silva for manuscript editing.

\section{Author details}

'Hospices Civils de Lyon, Hôpital Edouard Herriot, Service d'Hygiène, Epidémiologie et Prévention, Lyon, France. ${ }^{2}$ Institut d'Epidémiologie, Laboratoire de Biométrie et Biologie Evolutive, UMR CNRS 5558, Claude Bernard Lyon 1 University, Lyon, France. ${ }^{3}$ Groupement de laboratoires de biologie médicale libéraux DYOMEDEA, Lyon, France. ${ }^{4}$ Sanofi Pasteur MSD, Lyon, France.

Received: 30 May 2012 Accepted: 22 October 2012

Published: 1 November 2012

\section{References}

1. Guthmann JP, Fonteneau L, Antona D, Levy Bruhl D: La couverture vaccinale diphtérie, tétanos, poliomyélite chez l'adulte en France: résultats de l'enquête Santé et Protection Sociale, 2002. Bull Epidemiol Hebd 2007, 51-52:441-5.

2. Michel JP: Updated vaccine guidelines for aging and aged citizens of Europe. Expert Rev Vaccines 2010, 9(3 Suppl):7-10.

3. Launay O, Toneatti C, Bernède C, Njamkepo E, Petitprez K, Leblond A, et al: Antibodies to tetanus, diphtheria and pertussis among healthy adults vaccinated according to the French vaccination recommendations. Hum Vaccin 2009, 5(5):341-6.

4. Durand C, Flament E, Tournau C: Pertussis vaccination for parents: proposal and evaluation of two professional practices in a maternity hospital, Haute-Savoie (France), 2009. Bull Epidemiol Hebd 2010, 23:253-6.

5. Saadatian-Elahi M, Mekki Y, Del Signore C, Lina B, Derrough T, Caulin E, Thierry J, Vanhems P: Seroprevalence of antibodies among pregnant women in Lyon-France. Eur J Epidemiol 2007, 22:405-9.

6. Beytout J, Denis F, Giet R, Allaert FA: Regional variations of adult population vaccinal status. Med Mal Infect 2004, 34(10):460-8.

7. Six C: Organisation de la vaccination et mesure de la couverture vaccinale en région Provence-Alpes-Côte d'Azur. France: Saint-Maurice: Institut de veille sanitaire; 2011:54. http://www.invs.sante.fr/publications/2010/ couverture_vaccinale_paca/rapport_couverture_vaccinale_paca.pdf.

8. Antona D, Badeyan G, Bussière E, Grassullo V, Guerin N, Guignon N, et al: Mesure de la couverture vaccinale en France. Bilan des outils et méthodes en l'an 2000. France: Saint-Maurice: Institut de veille sanitaire: 2011:56. http://www.invs.sante.fr/publications/couverture_vaccinale/ couverture_vaccinale.pdf.

9. Guthmann JP, Fonteneau L, Ciotti C, Bouvet E, Pellissier G, Levy-Bruhl D, Abiteboul D: Vaccination coverage of health care personnel working in health care facilities in France: results of a national survey, 2009. Vaccine 2012, 30(31):4648-54

10. Guthmann JP, Fonteneau L, Antona D, Levy-Bruhl D: Factors associated with tetanus vaccination coverage in adults in France and with knowledge of vaccination status. Med Mal Infect 2010, 40(10):560-7.

doi:10.1186/1471-2458-12-940

Cite this article as: Baratin et al: Evaluation of adult dTPaP vaccination coverage in France: experience in Lyon city, 2010-2011. BMC Public Health 2012 12:940.

\section{Submit your next manuscript to BioMed Central and take full advantage of:}

- Convenient online submission

- Thorough peer review

- No space constraints or color figure charges

- Immediate publication on acceptance

- Inclusion in PubMed, CAS, Scopus and Google Scholar

- Research which is freely available for redistribution 